\title{
EXCESSIVE PRODUCT TRADING: A RARE FORM OF BEHAVIORAL ADDICTION
}

\author{
Ahmet Zihni Soyata ${ }^{1} \&$ Songül Derin ${ }^{2}$ \\ ${ }^{I}$ Department of Psychiatry, Ergani State Hospital, Diyarbakır, Turkey \\ ${ }^{2}$ Department of Child and Adolescent Psychiatry, Bezmialem Vakif University Medical Faculty, Istanbul, Turkey
}

received: 1.4.2021;

revised: 6.5.2021;

accepted: 17.5.2021

\section{INTRODUCTION}

Compulsive buying disorder $(\mathrm{CBD})$ is a repetitive, chronic buying behavior that may occur as a primary response to negative events and emotions, while craving and withdrawal symptoms may also be observed (Lejoyeux 2010). A variety of unusual behaviors may also coexist in individuals with CBD. However, reselling the products has not been reported. Herein, we report two excessive product trading cases.

\section{CASE 1}

A 39-year-old married college graduate male patient was admitted with complaints of nervousness, sadness, malaise, lack of energy, increased appetite and sleep, daytime sleepiness, guilt, remorse, worthlessness, pessimism and hopelessness thoughts.

He reported difficulties communicating with people due to sensitivity to criticism. He experienced palpitations, sweating and tremor during speaking in social places. He was afraid to speak his ideas, he did not feel comfortable in social environments because of the anxiety he experienced.

He stated that he had been buying electronic devices to sell them at a loss. The patient started buying electronic devices ten years ago. He realized that he felt a great deal of excitement and satisfaction during the purchase, and he made excessive purchases even though he was unable to sell. He started selling to the same people or others, even with a great loss, after he had accumulated so many items in his possession. Later, the patient realized that he had also been enjoying his sales. Activities other than buying and selling became undesirable and dissatisfied. A financial loss of 100000 United States Dollars (USDs) occured in the previous two months. He had to sell a house and three cars to pay off his debts. He received financial support from his family several times. He testified that he tried to hide his debts from his family, that there were fights due to the debts, and that he shouted at his wife and children, though he regretted this behaviors afterward. Despite these undesirable consequences, numerous quit attempts were unsuccessful.
Psychiatric history included a year-long depressive episode after he had been abandoned by his fiancée at the age of eighteen. Two years ago, he described an extended period of mourning that lasted four months after his father's death. He had no previous history of psychiatric treatment. He had no suicidal thoughts, attempts and self-mutilative behaviors. He had no other medical conditions. He had no history of alcohol and substance use. He had quit smoking three years earlier, despite smoking for a long time. He had no history of gambling. His family members had no history of psychiatric illness.

The patient was diagnosed as having major depressive disorder with atypical features, social anxiety disorder and impulse control disorder, not otherwise specified according to the Diagnostic and Statistical Manual of Mental Disorders-5 criteria. Treatment was arranged as fluoxetine 20 milligrams and risperidone 1 milligrams once a day. The motivational interview and cognitive behavioral therapy (CBT) aimed to raise awareness of cognitive distortions related to buying and selling. A month later, he had a partial recovery in his depressive symptoms. There was no new buying or selling behavior in the previous month, but his craving to buy and sell continued. Fluoxetine was increased to 40 milligrams. He had no depressive mood or anhedonia, no desire to buy. Sleep, increased appetite and lack of energy symptoms had disappeared. Symptoms of physiological and cognitive anxiety were reduced in social settings. Participating in joint activities with his family and friends and initiating new activities were planned. Three months later, there have been no behaviors of buying and selling at a loss.

\section{CASE 2}

A 28-year-old bachelor male patient working in a municipality admitted with a complaint of uncontrolled gambling that lasted for 13 years. The patient began gambling at sports betting shops and then focused on betting on live bets on the internet. He stated that he started to trade cell phones due to sensationseeking. Afterward, he realized that he felt arousal and excitement similar to betting during the trade of cell 
phones. The patient told that he had bought a large number of mobile phones from wholesaling stores, and then sold them to the shops at a loss. As a result, he had a total debt of about 50000 USDs. He borrowed from his friends and other people by showing his salary document as a guarantee. He still owned lots of mobile phones with an approximate value of 40000 USDs. His old mother began to work to pay his debts. He stated that he tried to quit these behaviors several times and only succeeded once which lasted two months.

The patient's psychiatric history included diagnoses of Attention Deficit Hyperactivity Disorder (ADHD) in childhood. There was no tobacco, alcohol or substance use. The patient was administered CBT and fluoxetine treatment and full remission of these behaviors were achieved. No relapses were observed in a year followup.

\section{DISCUSSION}

CBD and gambling disorder (GD) are nowadays evaluated within the behavioral addiction spectrum (Grant et al. 2006). Mounting evidence shows that disorders in this spectrum have similarities in epidemiological, phenomenological, psychological, neurobiological, and genetic features and the treatment responses (Yau \& Potenza 2015). Moreover, these disorders may exist together for an individual at the same time. Besides when more than one behavioral addiction is detected in the same individual, it is observed that neurobiological changes and destructive outcomes are greater. Recently, a growing body of literature indicates that a lot of behaviors may have addictive potential and pleasurable properties (Yau \& Potenza 2015). Therefore, it is recommended to observe the addictive potential and clinical manifestations of these behaviors. It is also considered that these behaviors may serve as facilitators for other addictive behaviors.

Individuals with CBD are more concerned with the purchasing process than ownership or the usage of the products (Lejoyeux et al. 1996). It is observed that individuals with CBD usually stocked purchased objects without opening their package or discarded them. Apart from these, the behavior of selling the products with a price lower than the purchasing prices was observed as a different behavior. The cases also reported that they felt arousal, excitement and pleasure similar to buying or gambling while selling the products and they were not able to quit this type of behavior despite several quit attempts.

The basics of compulsive buying include enjoying, as well as providing a sense of relief during times of depression (Lejoyeux 2010). Compulsive buying occurs as a response to negative emotions and then reduces the intensity of this negative emotion, creating a sense of relief and enjoyment. This relief is temporary and has often been observed that there is an aftermath of increased depression and anxiety. In the first case, atypical depression and sensitivity to rejection in interpersonal relationships played a triggering role and excessive product trading served as a relief. The striking aspect of present cases is the sense of arousal, excitement and pleasure similar to buying or gambling during the selling. In the second case, the accompanying diagnoses of GD and ADHD might have led to impulsivity, novelty-seeking and less harm-avoidance. Despite the losses after reselling, the quickly obtained cash from the sale might have acted as psychological and neurobiological rewarding stimuli and continuous selling at loss might be due to the dysfunction of the cortical reward and decision making mechanisms. Individuals with CBD had higher levels of impulsivity and ADHD symptoms along with the deficits of executive function (Black et al. 2012). It has also been observed that individuals with GD or CBD preferred shortterm rewards (Madden et al. 2011; Williams 2012). To conclude, deficits of executive functions and decision making might contribute to excessive product trading.

A case series have also been reported involving individuals who frequently trade with investment instruments that can be sold quickly, such as the stock market, foreign exchange or mutual funds (Guglielmo et al. 2016; Grall-Bronnec et al. 2017). It has been found that these individuals also exhibited similar characteristics with GD and performed highly risky transactions without considering the possible consequences. Similar to the first case we reported, comorbidities of major depressive disorder and social anxiety disorder were reported by Grall-Bronnec et al. It has also been reported that all cases had been male and that levels of novelty seeking had been high (Grall-Bronnec et al. 2017). Moreover, in recent years, there have been reports that the increase in cryptocurrency trading might lead to a similar pathological trading situation (Senarathne 2019; Mills \& Nower 2019). It has been proposed to evaluate and study this phenomenon as a different kind of addiction and a public health problem (Guglielmo 2016). However, the data on the clinical and neurobiological characteristics of these cases are scarce. Thus, excessive product trading merits further investigation and physicians should be aware of this condition.

\section{CONCLUSION}

Excessive product trading might be considered as a behavioral addiction. Further clinical data are needed to understand the phenomenological characteristics of excessive product trading.

\section{Acknowledgements:}

We would like to thank the patients for allowing their data to be shared.

\section{Conflict of interest: None to declare.}




\section{Contribution of individual authors:}

All authors made equal contribution to this case report in terms of drafting, writing, obtaining the patient's consent, and revising the paper.

\section{References}

1. Black DW, Shaw M, McCormick B, Bayless JD, Allen J. Neuropsychological performance, impulsivity, ADHD symptoms, and novelty seeking in compulsive buying disorder. Psychiatry Research. 2012; 200:581-587

2. Grall-Bronnec M, Sauvaget A, Boutin, C, et al. Excessive trading, a gambling disorder in its own right? A case study on a French disordered gamblers cohort. Addictive Behaviors 2017;64: 340-348

3. Grant JE, Brewer JA, Potenza MN. The neurobiology of substance and behavioral addictions. CNS Spectrums. 2006; 11:924-930

4. Guglielmo R, Ioime L, Janiri L. Is Pathological Trading an Overlooked Form of Addiction? Addiction \& Health. 2016; 8:207-209

5. Lejoyeux M, Ad'es J, Tassain V, Solomon J. Phenomenology and psychopathology of uncontrolled buying. American Journal of Psychiatry. 1996; 155:1524-1529

6. Lejoyeux M. Compulsive Buying. The American Journal of Drug and Alcohol Abuse. 2010;36, 248-253.

7. Madden GJ, Francisco MT, Brewer AT, Stein JS. Delay discounting and gambling. Behavioural Processes. 2011; 87:43-49

8. Mills DJ, Nower L. Preliminary findings on cryptocurrency trading among regular gamblers: A new risk for problem gambling? Addictive Behaviors 2019; 92:136-140

9. Senarathne $C W$. Gambling Behaviour in the Cryptocurrency Market. International Journal of Applied Behavioral Economics (IJABE), 2019; 8:1-16

10. Williams AD. Are compulsive buyers impulsive? Evidence of poor response inhibition and delay discounting. Journal of Experimental Psychopathology. 2012; 3: 794-806

11. Yau YH, Potenza MN. Gambling disorder and other behavioral addictions: recognition and treatment. Harvard Review of Psychiatry. 2015; 23:134-146
Correspondence:

Ahmet Zihni Soyata, MD

Department of Psychiatry, Ergani State Hospital

Adnan Menderes, 21950 Ergani, Diyarbakır, Turkey

E-mail:soyataaz@gmail.com 